\title{
AGRESSIVIDADE TRIBUTÁRIA E SUSTENTABILIDADE EMPRESARIAL NO BRASIL
}

\section{TAX AGGRESSIVENESS AND CORPORATE SUSTAINABILITY IN BRAZIL}

\author{
ANTONIO LOPO MARTINEZ \\ Doutor em Controladoria e Contabilidade pela Universidade de São \\ Paulo. Professor da Fucape Business School. Endereço: Av. \\ Fernando Ferrari, 1358 / Boa Vista | 29075505 / Vitória/ES / Brasil. \\ E-mail: lopo@fucape.br

\section{VINICIUS PEREIRA RAMALHO} \\ Mestre em Contabilidade pela Fucape Business School. Endereço: \\ Av. Fernando Ferrari, 1358 | Boa Vista | 29075505 / Vitória/ES / Brasil. \\ E-mail: vinicius.ramalho@gmail.com
}

\section{RESUMO}

A presente pesquisa tem como objetivo observar se a participação de empresas no Índice de Sustentabilidade Empresarial (ISE), listadas na BM\&FBovespa, define alguma espécie de comportamento no tocante à agressividade tributária. As empresas listadas, ou não, no ISE foram avaliadas no período de 2010 a 2014 por meio de duas medidas de agressividade tributária: a taxa efetiva de tributação ETR (Effective tax Rate) e a diferença entre os Lucros Contábeis e o Tributário (Book Tax Differences - BTD). Por hipóteses, especulava-se que as empresas listadas no índice seriam menos agressivas tributariamente, com o propósito de sinalizar um comportamento coerente com uma preocupação social. Entretanto, não foi encontrada uma teoria racional para justificar essa relação antecipada e, na verdade, sustentabilidade empresarial, em certa medida, poderia inclusive, estar relacionada com um planejamento tributário mais eficiente. A agressividade fiscal envolve o emprego de técnicas que privilegiam o planejamento tributário com vistas a reduzir a tributação explicita. Em certas circunstâncias empregam-se técnicas legais (elisão) e outras ilegais, seja por sua abusividade na forma ou mesmo por ter caráter evasivo com vistas a reduzir a carga tributária. Os resultados documentados na pesquisa indicaram que as empresas que compõem o ISE tendem a ser menos agressivas tributariamente relativamente àquelas que não participam do ISE. Esse achado serve para antecipar o comportamento tributário de uma empresa em função dos valores que prestigia.

Palavras-chave: Agressividade fiscal. Lucro contábil. Sustentabilidade. Planejamento fiscal.

\section{ABSTRACT}

The present research aims to observe whether the participation of companies in the Corporate Sustainability Index (ISE) listed in BM\&FBovespa defines behavior regarding tax aggressiveness. The companies listed or not in ISE were evaluated in the period from 2010 to 
2014 through two measures of tax aggressiveness: the effective tax rate ETR (Effective tax Rate) and the difference between Book Tax Differences - BTD). By hypothesis, it was speculated that the companies listed in the index would be less tax aggressive to signal a behavior consistent with a social concern. However, a rational theory was not found to justify this anticipated relationship, and in fact, corporate sustainability, to a certain extent, could even be related to more efficient tax planning. Fiscal aggressiveness involves the use of techniques that privilege tax planning to reduce its explicit taxation, and in certain circumstances legal techniques (elision) and other illegal techniques are used, either because of their abusiveness in form or even because they have character to reduce the tax burden. The results documented in the research indicated that the companies that make up the ISE tend to be less tax aggressive those that do not participate in the ISE. This finding serves to anticipate the tax behavior of a company in function of the values that it prestige.

Keywords: Tax aggressiveness. Accounting profit. Sustainability. Tax planning.

\section{INTRODUÇÃO}

Nota-se em nossos dias uma preocupação crescente com uma atuação empresarial sustentável. De modo geral, associa-se a sustentabilidade à promoção de práticas que zelam pelos interesses da comunidade que envolvem aspectos sociais e ambientais. Entretanto, resta a dúvida de como aquelas empresas, que possuem um discurso orientado para a sociedade, se comportam no aspecto tributário, ou melhor, no relativo ao que pagam de tributos. Haveria uma associação entre a sustentabilidade empresarial e o comportamento fiscal das empresas?

Isso posto, a proposta desta pesquisa é apreciar a agressividade fiscal das empresas consideradas sustentáveis e listadas no Índice de Sustentabilidade Empresarial (ISE) na BM\&FBovespa. O ISE foi criado em 2005, pela BM\&FBovespa e por um conjunto de instituições. Esse índice tornou-se referência para os investimentos socialmente responsáveis no Brasil, com o objetivo de demonstrar o retorno de uma carteira que tem a composição, ações de empresas com um comportamento que promovam o bem-estar do público externo e interno e também que adotem boas práticas na gestão empresarial no Brasil.

Participam do ISE empresas que se destacam pelo compromisso com o desenvolvimento sustentável, juntamente com as ações de estratégias empresariais no Brasil. A BM\&FBovespa divulga esse índice como referência de melhores práticas de sustentabilidade. Busca indicar uma relação de investimento que se ajuste com as demandas referentes a um crescimento sustentável da sociedade presente (Bovespa, 2016).

Conforme Dias (2006), a promoção de boas práticas ambientais tornou-se importante. Constitui um objetivo estratégico de várias organizações. Também, de forma indireta, quando são percebidos os impactos do meio ambiente de forma prejudicial, os quais as empresas provocam para o seu desenvolvimento. Isso faz com que desperte na sociedade maior conscientização para esse tipo de problema.

Lima (2014) descreve que a companhia deve sofrer alterações diante dos padrões da administração e na aplicação de deliberações da empresa. Não só é relevante a parte do desempenho econômico financeiro, como também leva-se em conta a área voltada para a sociedade e o meio ambiente.

O comportamento das empresas está refletindo uma conscientização crescente no que se refere à esgotabilidade dos recursos considerados naturais. Conforme Coral (2002), a empresa deverá modificar os seus modelos de gestão e tomada de decisão, considerando não somente os aspectos econômicos, mas também os sociais e ambientais.

Na sequência será apresentado o referencial teórico, e a hipótese de pesquisa. A seguir serão discutidos aspectos metodológicos do estudo a ser desenvolvido. Na continuação são apresentados os resultados e análises são efetuadas. Finalmente será apresentada a conclusão, que aponta as principais descobertas. 


\section{REFERENCIAL TEÓRICO}

O referencial teórico será exposto brevemente. Primeiramente será discutido o Índice de Sustentabilidade Empresarial - ISE e posteriormente a questão da agressividade fiscal.

\section{1 Índice de Sustentabilidade Empresarial - ISE}

Medindo o retorno em média de uma composição de ações das empresas que operam no Brasil e de capital aberto, presentes na BM\&FBovespa, o ISE regula as práticas em sustentabilidade e direciona também as melhores abordagens para uma performance mais corporativa em relação aos efeitos sobre a economia e o equilíbrio do meio ambiente.

Não obstante, as empresas passaram a ressaltar os critérios voltados para as sociedades, para o meio ambiente e a adotar critérios ecológicos com maior cuidado. A sustentabilidade coorporativa ganha força a partir do momento em que o empresário entende que somente os índices de rentabilidade não são mais suficientes para planejamentos estratégicos de longo prazo.

Lima (2014) descreve que a forma de se alterar os procedimentos dos usuários, das pessoas, é direcionar remotamente uma alteração do conjunto interno da organização da empresa, estabelecendo que essa, se torne propícia a se adaptar ao momento da oferta e da procura diante da sociedade, visando não apenas o valor financeiro dos produtos para se avaliar sobre a concorrência.

Em se tratando de um mundo consumista, a análise vai mais adiante sobre os atributos e o valor do produto, quando se leva em conta o meio ambiente e suas influências para o consumo final.

Para fazer parte da carteira do ISE, as empresas terão que atender a critérios cumulativamente, ao ponto de serem classificadas conforme um Conselho específico, presidido pela BMF\&Bovespa, o qual é o responsável pelos fatos que geram desenvolvimento por parte do Índice. Assim, as empresas listadas de maior negociação para a emissão das 200 ações nos últimos 12 (doze) meses serão avaliadas de acordo com seu desempenho, mostrando se a empresa publica seus balanços sociais, levando em consideração o produto que ela fornece, se não acarreta riscos ou danos à saúde daqueles que o consomem. É levado em consideração também como as empresas buscam o alinhamento das preocupações e o aperfeiçoamento nas tomadas de decisão na firma sobre um ambiente sustentável. A negociação deve ser feita em pelo menos $50 \%$ dos pregões incididos nos 12 doze meses anteriores ao início do processo de reavaliação, também como critério para avaliação e inclusão no ISE (Bovespa, 2016).

Deixará de compor o ISE a empresa que descumprir qualquer um dos critérios de inclusão; enquanto estiver vigente a carteira, ingressar em regime de falências ou recuperação judicial; no caso de oferta pública, proceder em retirada de movimentação de parcela que seja significativa de ações do mercado ou suspensão do que seja negociado pela referente ação por mais de 50 dias.

\subsection{Agressividade fiscal}

Os impostos se tornam fatores de motivação em muitas decisões corporativas. Ações gerenciais exclusivamente destinadas a minimizar os impostos corporativos por meio de práticas de agressividade fiscal estão se tornando cada vez mais comuns no panorama empresarial em todo o mundo. Não obstante, um planejamento com agressividade fiscal pode gerar custos e benefícios. Do ponto de vista social, o pagamento de impostos corporativos assegura o financiamento dos bens públicos (Freise, Link, \& Mayer, 2008). Assim, políticas com práticas fiscais mais agressivas de uma corporação, pode ter um efeito negativo na sociedade (Freedman, 2003; Slemrod, 2004; Landolf, 2006).

Para Freedman (2003), Freise et al. (2008) e Gilders, Taylor, Richardson, \& Walpole (2004), a agressividade fiscal é forte em uma empresa, cujo seu planejamento tributário visa à redução dos pagamentos dos impostos afetando o repasse de recursos para o governo, o qual é a principal parte interessada. Pode causar prejuízos futuros quando relacionados à sociedade, como o retorno em bens públicos. 
De acordo com Williams (2007), quando uma empresa tem atitude de forma ética relacionada em suas atividades operacionais e demonstra sua postura na conjuntura econômica e financeira, isso acarreta um resultado positivo sobre os negócios com os investidores e também reflete uma melhor relação com a sociedade de forma geral.

A agressividade fiscal, para Chen, Chen, Cheng e Shevlin (2010), é um conjunto de atividades que direcionam a redução dos pagamentos dos impostos mediante planejamento tributário. Segundo Slemrod e Yitzhaki (2002) e Slemrod (2004), agressividade fiscal é conceituada como uma ampla gama de operações com o único objetivo de reduzir o total da dívida tributária.

No Brasil, existem duas maneiras de as empresas reduzirem seus gastos com tributos: usando técnicas de elisão (forma legal) ou pela evasão (forma ilegal). No entanto, há alguns anos, com a instituição de mecanismos antielisivos no código tributário brasileiro, as autoridades fiscais têm conseguido conter ou desconstituir alguns atos praticados pelos contribuintes, sob o argumento da utilização de técnicas de elisão fiscal artificial (ou elusiva). Entretanto, é comum encontrar divergências de entendimentos entre legisladores e juristas no que tange a aplicação desses mecanismos, como exposto em Schoueri (2010).

\begin{tabular}{|l|l|}
\hline Elisão Fiscal (Planejamento Tributário) & Evasão Fiscal (Sonegação Fiscal) \\
\hline${ }^{*}$ Legal & ${ }^{*}$ llegal (contrário às leis) \\
\hline${ }^{*}$ Não é passível de repressão & $\begin{array}{l}{ }^{*} \text { Passível de medida repressiva (crime de sonegação } \\
\text { fiscal) }\end{array}$ \\
\hline${ }^{*}$ Medida adotada antes de ocorrer o fato gerador & ${ }^{*}$ Medida adotada após ocorrer o fato gerador. \\
\hline * Precisa ser estimulada & ${ }^{*}$ Precisa ser combatida \\
\hline
\end{tabular}

Figura 1. Elisão Fiscal e Evasão Fiscal

Fonte: Adaptado de Amaral, G. L. (2007). Seminário nacional de excelência na gestão tributária. Instituto Brasileiro de Planejamento Tributário - IBPT, Curitiba, PR, 18.

Os impostos são fatores de motivação em certas decisões corporativas. Ações gerenciais direcionadas a minimizar os impostos por meio de agressividade fiscal estão se tornando práticas ordinárias comuns no cenário empresarial global. A despeito do tema sugerido, um planejamento com agressividade fiscal pode gerar custos e benefícios. Do ponto de vista social, o pagamento de impostos corporativos assegura o financiamento dos bens públicos (Freise et al., 2008).

\subsubsection{Effective Tax Rate - ETR}

Como proxy para medir a agressividade fiscal das empresas será utilizada a taxa de imposto efetiva (ETR - Effective Tax Rate). Essa métrica envolve as despesas com imposto de renda e contribuição social sobre o lucro líquido (IR/CSLL) sobre o LAIR, o lucro antes do imposto de renda.

Com base nessa motivação, também será utilizada a ETR como métrica para a medição da agressividade fiscal nas companhias. Giannini e Maggiulli (2002) afirmam que a ETR pode ser adotada para se avaliar o real impacto da carga tributária das empresas, além de explicar os seus efeitos nas tomadas de decisões.

\subsubsection{Book-Tax Differences - BTD}

Como proxy de agressividade fiscal, a BTD será utilizada para mensurar o nível de agressividade nas empresas.

A utilização desta proxy fundamenta-se na pesquisa de Dunbar, Higgins, Phillips, \& Plesko (2010) os quais definem Book-Tax Differences como uma das medidas para a mensuração da agressividade fiscal.

BTDs são as diferenças entre os Lucros Contábeis e o Tributário. Essas diferenças são decorrentes de formas diversas nas apurações. Enquanto o Lucro Contábil é obtido por meio do resultado das receitas menos os custos e as despesas, o Lucro Tributário é apurado a partir do Lucro Contábil, ajustado pelas adições e exclusões exigidas e permitidas pela lei do imposto 
de renda. (Dalfior, 2015). Motivado pela literatura existente, utilizar-se-á a BTD como medida de agressividade fiscal.

Inobstante se reconheça pertinente, o argumento de que se uma empresa possui um lucro tributável menor do que o lucro contábil, se aplicado os mecanismos legais (elisão), significa apenas que a empresa possui planejamento e não que é agressiva do ponto de vista fiscal. A realidade é que essa métrica é utilizada generalizadamente pela literatura internacional como uma medida de agressividade fiscal.

\subsection{Hipótese de pesquisa}

Por conta do referencial apresentado, deseja-se investigar se as organizações listadas no índice de sustentabilidade empresarial em questão são mais conservadoras e se possuem comportamento fiscal menos agressivo do que aquelas não pertencentes. Com isso, será apresentada a hipótese a ser testada:

H1: Empresas listadas no Índice de Sustentabilidade Empresarial são tributariamente menos agressivas do que as empresas não pertencentes a esse grupo.

Almeja-se verificar se de algum modo a listagem no segmento especial implica em algum comportamento em termos de agressividade tributária dessas empresas.

\section{METODOLOGIA}

A pesquisa consiste em uma análise descritiva. Toma como base o método quantitativo para análise e utiliza instrumentos de informações estatísticas.

A coleta de dados e a análise serão baseadas em informações contábeis por uma amostra dos anos de 2010 a 2014, com empresas listadas na Bolsa de Valores de São Paulo Bovespa.

Assumiu-se, por hipótese, que a BTD e a ETR são indicadores utilizáveis na análise da agressividade fiscal. Essa hipótese sustenta-se nas conclusões dos estudos de Chen et al. (2010), Hanlon et al. (2012) e Ferreira, Martinez e Moraes (2012).

\subsection{Seleção da amostra}

Os dados foram extraídos do banco de dados da Economática ${ }^{\circledR}$ para a população pesquisada e demais empresas listadas na BM\&FBovespa, cujo período foi de 2010 a 2014. Antes do processo de seleção foram excluídas as empresas desse período das quais não havia informação.

Inicialmente a escolha do ano de 2010 justifica-se por ser o período em que as normas contábeis já se encontravam padronizadas com as normas internacionais. A seleção até o ano de 2014 por ser o período mais recente quanto aos dados publicados para análise. Foram utilizadas duas métricas para a mensuração da agressividade fiscal. São elas: a BTD e a ETR.

\begin{tabular}{|l|l|l|}
\hline MÉTRICAS & CÁLCULO & DEFINIÇÃO \\
\hline ETR - effective tax rate & $\begin{array}{l}\text { Despesa total com imposto de renda e } \\
\text { contribuição social sobre lucro líquido / } \\
\text { Lucro antes do Imposto }\end{array}$ & $\begin{array}{l}\text { Reflete a taxa efetiva de imposto pago, } \\
\text { atrelado ao lucro antes do imposto. }\end{array}$ \\
\hline BTD - book tax difference & BTD= LAIR - (desp IRPJ e CSLL/0,34) & $\begin{array}{l}\text { Reflete o lucro contábil menos o lucro } \\
\text { tributável, escalonados pelos ativos de } \\
\text { cada empresa. }\end{array}$ \\
\hline
\end{tabular}

Figura 2. Métricas de Agressividade Fiscal

Fonte: Autores. 
A coleta desses dados será relevante para justificar a hipótese esperada da pesquisa, a qual mostra a avaliação da agressividade fiscal e espera que as empresas participantes do Índice de Sustentabilidade Empresarial sejam menos agressivas tributariamente.

\section{Tabela 1}

\section{Identificação e Composição da Amostra}

Definição

Quantidade

Números gerais das empresas

(-) Exclusão de empresas sem informações

(-) Exclusão de empresas com ETR negativo

(=) Total após exclusão

(X) Quantidade de períodos (anos)

(=) Quantidade de Observações Utilizadas

535

Nota. Fonte: Informações da Pesquisa e Autores.

\subsection{Modelos de regressão}

Para indicar a relação existente entre as empresas listadas no ISE com a agressividade fiscal, foi utilizada, conforme o modelo abaixo, uma regressão linear múltipla. Diferentes variáveis explicativas podem ser utilizadas no sentido de prever o valor de uma variável dependente.

O modelo apresentado será empregado para visualizar a agressividade fiscal para as empresas listadas no ISE, utilizadas as variáveis de controle.

$$
\begin{aligned}
\text { Taxa Aggr }= & \beta 0+\beta 1 S U S T+\beta 2 R O A+\beta 3 L E V E R A G E+\beta 4 P P E+\beta 5 \text { INTANG } \\
& +\beta 6 S I Z E+\varepsilon
\end{aligned}
$$

\begin{tabular}{|l|l|}
\hline \multicolumn{1}{|c|}{ Medida } & \multicolumn{1}{c|}{ Cálculo } \\
\hline SUST & $\begin{array}{l}\text { Empresas participantes do Índice de Sustentabilidade Empresarial - ISE, 1 } \\
\text { para empresas listadas no ISE e 0 para as demais }\end{array}$ \\
\hline ROA - return on assets & Lucro operacional dividido pelo ativo \\
\hline LEV - leverage & Alavancagem, avaliada como a dívida de longo prazo. \\
\hline $\begin{array}{l}\text { PPE - plant, property and } \\
\text { Equipment }\end{array}$ & Ativo imobilizado dividido pelo ativo total \\
\hline INTANG & Ativo intangível; dividido pelo ativo total \\
\hline SIZE & Logaritmo natural do valor de mercado da empresa. \\
\hline$\varepsilon$ & Fatores residuais e erro de medição \\
\hline
\end{tabular}

Figura 3. Variáveis de Controle

Fonte: Autores.

\section{ANÁLISE DOS RESULTADOS}

Neste item serão apresentadas as estatísticas descritivas e a análise dos resultados do modelo de regressão proposto.

\subsection{Estatísticas descritivas}

Neste capítulo serão abordados os resultados documentados nesta pesquisa, expostos na tabela abaixo, na qual a estatística descritiva das variáveis é apresentada para uma amostra de 535 observações, com um total de 107 empresas para o período de 2010 a 2014.

Destaca-se na tabela 2 a estatística descritiva de todas as observações coletadas. A contagem resultante em 535 foi obtida pelo período dos cinco anos, ou seja, referente às 107 empresas por ano, incluindo a ETR - Effctive tax rate como métrica de agressividade tributária, com o objetivo de utilizar essa métrica em relação às outras variáveis de controle. 
Tabela 2

Estatística Descritiva

\begin{tabular}{llllllll}
\hline & ETR & SUST & ROA & LEV & PPE & INTANG & SIZE \\
\hline Média & 0,3746 & 0,1477 & 3,8471 & 29,9091 & 0,2432 & 0,1259 & 14,4829 \\
Erro padrão & 0,0477 & 0,0154 & 0,5494 & 0,7005 & 0,0094 & 0,0083 & 0,0777 \\
Mediana & 0,2644 & 0,0000 & 4,6016 & 29,9675 & 0,2073 & 0,0292 & 14,7025 \\
Desvio padrão & 1,1030 & 0,3551 & 12,7067 & 16,2018 & 0,2170 & 0,1930 & 1,7973 \\
Variância da amostra & 1,2165 & 0,1261 & 161,4597 & 262,4999 & 0,0471 & 0,0372 & 3,2303 \\
Contagem & 535 & 535 & 535 & 535 & 535 & 535 & 535 \\
\hline
\end{tabular}

Nota. Fonte: Dados da pesquisa e Autores.

Na Tabela 3, demonstrada abaixo, foram separadas as empresas que fazem parte da carteira do Índice de Sustentabilidade daquelas que não o fazem, com o objetivo de apresentar a média das variáveis. Foi utilizada a variável dummy, ao passo que foram identificadas por 0 aquelas empresas que estão fora da carteira do ISE e por 1 aquelas que pertencem ao Índice.

Tabela 3

\begin{tabular}{lccc}
\multicolumn{4}{l}{ Médias das Variáveis } \\
\hline \multicolumn{1}{c|}{ VARIÁVEIS } & FORA DO ISE - 0 & NO ISE - 1 & Total \\
\hline ETR & 0,3497 & 0,5182 & 0,3746 \\
ROA & 3,6240 & 5,1348 & 3,8471 \\
LEV & 29,7287 & 30,9503 & 29,9091 \\
PPE & 0,2400 & 0,2614 & 0,2432 \\
INTANG & 0,1129 & 0,2005 & 0,1259 \\
SIZE & 14,2301 & 15,9421 & 14,4829
\end{tabular}

Nota. Fonte: Dados da pesquisa e Autores.

\subsection{Resultados do modelo de regressão}

\subsubsection{Resultados ETR}

Para os resultados do modelo de regressão, foi apresentada a matriz de correlação, conforme a Tabela 4, indicando uma correlação positiva entre as empresas que estão listadas no ISE e a ETR - effective tax rate. Na medida em que a empresa é menos agressiva tributariamente (ou seja, maior ETR), ela tende a ser listada no ISE (Dummy =1). Com isso sua interpretação torna esperado que a agressividade fiscal esteja relacionada com a listagem do ISE - índice de sustentabilidade empresarial, tendo como métrica utilizada a ETR.

Tabela 4

Matriz de Correlação - ETR

\begin{tabular}{llllllll}
\hline & ETR & SUST & ROA & LEV & PPE & INTANG & SIZE \\
\hline ETR & 1 & & & & & & \\
SUST & 0.0542 & 1 & & & & & \\
ROA & -0.0172 & 0.0422 & 1 & & & & \\
LEV & 0.1522 & 0.0268 & -0.1250 & 1 & & & \\
PPE & -0.0193 & 0.0350 & -0.1181 & 0.0831 & 1 & & \\
INTANG & -0.0055 & 0.1611 & 0.0334 & 0.0607 & -0.3391 & 1 & \\
SIZE & -0.0859 & 0.3382 & 0.3202 & -0.0441 & -0.1805 & 0.2598 & 1 \\
\hline
\end{tabular}

Nota. Fonte: Dados da pesquisa e Autores. 
Todas as observações que contribuíram para esta pesquisa foram submetidas a métricas, que do mesmo modo estiveram presentes em trabalhos como os de Chen et al. (2010) e Martinez e Ramalho (2014), a fim de analisar a sua hipótese. O resultado confirma o esperado pela pesquisa. Demonstra que as empresas listadas no segmento do ISE são menos agressivas tributariamente.

Conforme a Tabela 5, o coeficiente SUST é positivo e significativo, no valor de 0,3026 com $p$-valor de 0,0345 . Isso implica que as empresas que compõem a carteira do ISE tendem a apurar um ETR maior. Significa que são menos agressivas em termos tributários.

Tabela 5

\section{Regressão em relação à ETR}

\begin{tabular}{llll}
\hline VARIÁVEL & COEFICIENTES & ESTATÍSTICA T & $P$-VALOR \\
\hline INTERCEPTO & 1,2374 & 2,7709 & 0,0058 \\
SUST & 0,3026 & 2,1201 & 0,0345 \\
ROA & 0,0028 & 0,7141 & 0,4755 \\
LEV & 0,0105 & 3,5629 & 0,0004 \\
PPE & $-0,3116$ & $-1,3237$ & 0,1862 \\
INTANG & $-0,1087$ & $-0,4043$ & 0,6862 \\
SIZE & $-0,0789$ & $-2,5999$ & 0,0096 \\
\hline
\end{tabular}

Nota. Fonte: Dados da pesquisa e Autores.

O resultado apresentado pela variável $L E V$ teve um coeficiente positivo e significativo de 0,0105 , com $p$-valor de 0,0004. Esse resultado demonstrou que as empresas mais alavancadas tendem a ser menos agressivas. O resultado do coeficiente da variável SIZE é negativo e significativo com um $P$-valor de 0,0096 . Isso indica que quanto maior é o tamanho das companhias, menor será a ETR, e consequentemente maior será a agressividade fiscal. Os coeficientes do ROA, PPE e INTANG não foram significativos em relação à ETR.

\subsubsection{Resultados BTD}

Conforme análise do BTD, Tabela 6 , os resultados obtidos nessa métrica não foram conclusivos, tendo em vista que não foi encontrada relação significativa.

Tabela 6

\section{Regressão em relação ao BTD}

\begin{tabular}{lllll}
\hline VARIÁVEL & Coeficientes & Erro padrão & ESTATÍSTICA T & $P$-VALOR \\
\hline INTERCEPTO & $-0,0301$ & 0,0188 & $-1,5983$ & 0,1105 \\
SUST & 0,0017 & 0,0066 & 0,2574 & 0,7969 \\
ROA & 0,0088 & 0,0002 & 51,0145 & 0,0000 \\
LEV & 0,0003 & 0,0001 & 2,8390 & 0,0047 \\
PPE & $-0,0054$ & 0,0104 & $-0,5159$ & 0,6061 \\
INTANG & $-0,0294$ & 0,0123 & $-2,3969$ & 0,0168 \\
SIZE & 0,0007 & 0,0013 & 0,5722 & 0,5674 \\
\hline
\end{tabular}

Nota. Fonte: Dados da pesquisa e Autores.

O resultado apresentado pela variável ROA teve um coeficiente de 0,0088 positivo, garantido por um $p$-valor de 0,0000 . Expressa uma relação positiva e significativa entre o ROA e o BTD.

O coeficiente apresentado pela variável LEV foi de 0,0003 positivo, garantido por um $p$-valor de 0,0047. A relação é inversamente proporcional entre a alavancagem da métrica destacada e o BTD. Para a variável INTAG o coeficiente foi de $-0,0294$ negativo, garantido por um $p$-valor de 0,0168 . 
Para as variáveis SUST, PPE e SIZE, apesar dos coeficientes estarem dentro do intervalo de $95 \%$ de confiança, o $p$-valor dessas variáveis ficou acima de $5 \%$. Indica que elas não são significativas em relação ao BTD.

Esse indicador apresenta o percentual de economias tributárias, a priori. No entanto, recomenda-se cuidado na interpretação dos resultados, pois as diferenças podem representar economias tributárias temporárias; elas podem ser decorrentes de diferenças temporárias tributáveis ou dedutíveis. Há, assim, apenas um benefício fiscal intertemporal para a empresa postergação ou antecipação dos tributos.

Urge recordar que as Book-tax differences ocorrem não só por causa dos diferentes objetivos das normas de contabilidade financeira e de regras fiscais. Portanto, é importante, em estudos alternativos, investigar os outros motivos que podem conduzir a essas diferenças. As razões mais importantes são o gerenciamento de resultados, o gerenciamento tributário, as estratégias gerenciais e a consolidação de normas.

\section{CONCLUSÃO}

A pesquisa destacou o compromisso com o desenvolvimento sustentável realizado pelas empresas listadas no Índice de Sustentabilidade Empresarial (ISE) da BM\&FBovespa, visando a avaliar se essas são mais ou menos agressivas tributariamente, ou seja, buscam uma redução da carga tributária explícita por meio de práticas de planejamento tributário. A participação das empresas na carteira do ISE era, por hipótese, avaliada como sinalizador de que essas empresas, listadas nesse segmento seriam menos agressivas tributariamente. Os resultados comprovaram essa relação com 95\% de confiança em relação à Taxa Efetiva de Tributação (ETR). Os achados ainda demonstram de maneira mais específica a presença significativa de empresa listada no ISE com características de menor agressividade tributária.

Isso posto, esta pesquisa evidenciou que empresas que se envolvem com a sustentabilidade são menos sujeitas a passivos fiscais e, por conseguinte, são propensas a riscos menores que as demais. Urge destacar que os preços das ações são sensíveis às informações contábeis e à posturas de risco. Empresas sustentáveis seriam menos arriscadas, impactando positivamente no custo de capital e no seu próprio valor.

Não foi encontrada uma teoria racional robusta para justificar essa relação antecipada. A agressividade fiscal envolve o emprego de técnicas que privilegiam o planejamento tributário com vistas a reduzir a sua tributação explícita. Em certas circunstâncias empregam-se técnicas legais (elisão) e outras ilegais, seja por sua abusividade na forma ou mesmo por ter caráter evasivo com vista a reduzir a carga tributária.

Os resultados documentados na pesquisa indicaram que as empresas que compõem o ISE tendem a ser menos agressivas tributariamente em relação àquelas que não participam do ISE. Constitui um importante achado. Para reguladores, investidores e a comunidade em geral servem para auxiliar a antecipar o comportamento tributário de uma empresa.

Futuras pesquisas devem aprofundar a análise dos critérios que definem uma empresa como participante do segmento especial do ISE da BM\&FBovespa, e buscar identificar se existe uma correlação entre a agressividade tributária e as diversas dimensões sobre as quais as carteiras das empresas que participam do Índice de Sustentabilidade Empresarial (ISE) são definidas. É esperado que em alguns segmentos a preocupação com a sinalização de agressividade seja mais marcante, enquanto que em outros um sinal reverso poderá ser identificado.

\section{REFERÊNCIAS}

Amaral, G. L. (2007). Seminário nacional de excelência na gestão tributária. Instituto Brasileiro de Planejamento Tributário - IBPT, Curitiba, PR, 18.

Bolsa de Valores de São Paulo (Bovespa). Recuperado em 15 de fevereiro, 2016, de http://www.bmfbovespa.com.br/Indices/download/Apresentacao-ISE.pdf 
Chen, S., Chen, X., Cheng, Q., \& Shevlin, T. (2010) Are family firms more tax agressive than nonfamily firms? Journal of Financial Economics, 95, 41-61.

Coral, E. (2002) Modelo de Planejamento Estratégico para Sustentabilidade Empresarial. Tese de Doutorado, Universidade Federal de Santa Catarina. Santa Catarina, Florianópolis, SC, Brasil.

Dalfior, M. D. (2015). Análise da agressividade fiscal entre controladoras e controladas. Dissertação de Mestrado, Fundação Instituto Capixaba de Pesquisas em Contabilidade, Economia e Finanças - FUCAPE, Vitória, ES, Brasil.

Dunbar, A., Higgins, D., Phillips, J., \& Plesko, G. (2010). What do measures of tax aggressiveness measure. In Proceedings of the National Tax Association Annual Conference on Taxation (pp. 18-26).

Dias, R. (2006). Gestão ambiental: responsabilidade social e sustentabilidade. São Paulo: Atlas.

Ferreira, F. R., Martinez, A. L., \& Moraes, F. (2012). Book-tax differences e gerenciamento de resultados no Mercado de ações do Brasil. Revista de administração de empresas, 52(5), 488-501.

Freedman, J. (2003) Tax and corporate responsibility. Tax Journal, 695(2), 1-4.

Freise, A., Link, S., \& Mayer, S. (2008). Taxation and corporate governance - The state of the art. In W. Schön (Ed.), Tax and Corporate Governance. Springer-Verlag, Berlin Heidelberg.

Giannini, S., \& Maggiulli, C. (2002). Effective tax rates in the EU Commission Study on company taxation: Methodological aspects, main results and policy implications. CESifo Economic Studies, 48(4), 633.

Gilders, F., Taylor, J., Richardson, G., \& Walpole, M., (2004). Understanding Taxation Law: An Interactive Approach (2nd ed.). LexisNexis Butterworths, Sydney, NSW.

Hanlon, M., \& Heitzman, S. (2010). A review of tax research. Journal of Accounting and Economics, 50(2), 127-178. doi: 10.1016/j.jacceco.2010.09.002

Landolf, U. (2006). Tax and corporate responsibility. International Tax Review, 29, 6-9.

Lima, S. C. de. (2014). Uma análise bibliométrica do tema sustentabilidade nos periódicos de gestão e contabilidade no Brasil. Dissertação de Mestrado, Fundação Instituto Capixaba de Pesquisas em Contabilidade, Economia e Finanças - FUCAPE, Vitória, ES, Brasil.

Martinez, A. L., \& Ramalho, G. C. (2014). Family Firms and Tax Aggressiveness in Brazil. International Business Research, 7(3), 129-136. doi: 10.5539/ibr.v7n3p129

Schoueri, L. E. (2010). Planejamento Tributário e o Propósito Negocial. São Paulo: Quartier Latin.

Slemrod, J. (2004). The economics of corporate tax selfishness. National Bureau of Economic Research.

Slemrod, J., \& Yitzhaki, S. (2002). Tax avoidance, evasion, and administration. Handbook of public economics, 3, 1423-1470.

Williams, D.F. (2007). Developing the Concept of Tax Governance. KPMG, London, UK. 